\title{
PERSEPSI MASYARAKAT TERHADAP HOAX BIDANG KESEHATAN
}

\author{
Haikal $^{1}$, Muhammad Iqbal ${ }^{2}$ \\ ${ }^{1}$ Staf pengajar Fakultas Kesehatan Universitas Dian Nuswantoro \\ email : haikalfaqih@dsn.dinus.ac.id
}

\begin{abstract}
The Indonesian Journalists Association survey places health content that contains the most hoax information. Hoax in the health sector is considered more dangerous than other types of hoax. This study aims to describe the perception of the community in RW 10, Tanjung Mas Village on the Hoax News in the Health Sector. The type of research used is descriptive-qualitative research. Techniques in data collection using literature study and in-depth interviews. The results showed that Facebook and Whatsapp Group are the media most containing hoaxes. The most common hoaxes are related to alternative medicine, prohibitions against something and prohibitions on consuming something at the same time. Education and law enforcement are ways to overcome hoax problems in the health sector.

Keywords: Perception, Misinformation, Community.
\end{abstract}

\begin{abstract}
ABSTRAK
Survei Persatuan Wartawan Indonesia menempatkan konten kesehatan sebagai konten yang paling banyak mengandung informasi hoax. Hoaks bidang kesehatan lebih berbahaya dibanding hoaks lain karena dapat mengancam jiwa seseorang. Penelitian ini bertujuan untuk mendeskripsikan persepsi masyarakat di RW 10 Kelurahan Tanjung Mas terhadap berita Hoax Bidang Kesehatan. Jenis penelitian yang digunakan yaitu penelitian deskriptif-kualitatif. Teknik pengumpulan data menggunakan studi kepustakaan dan wawancara mendalam. Hasil penelitian menunjukkan bahwa. Facebook dan Whatsapp Group menjadi media yang paling sering dijumpai mengandung hoax. Hoax yang paling sering dijumpai terkait dengan pengobatan alternatif, larangan terhadap sesuatu dan larangan untuk mengonsumsi sesuatu secara bersamaan. Edukasi/Sosialisasi dan penegakan hukum menjadi cara yang dapat dilakukan untuk mengatasi permasalahan hoax bidang kesehatan.
\end{abstract}

Kata kunci: Persepsi, Hoax Kesehatan, Masyarakat. 


\section{PENDAHULUAN}

Pada tahun 2017, Persatuan Wartawan Indonesia merilis hasil survei yang menempatkan konten kesehatan diperingkat pertama sebanyak $27 \%$ sebagai konten paling banyak terdapat unsur hoax-nya. Konten politik serta hiburan berada diposisi kedua dan ketiga dengan nilai $22 \%$ dan $15 \%$ (Indonesia, 2017). Selain itu, berdasarkan survei dari Masyarakat Telematika Indonesia, media yang digunakan untuk penyebaran hoax ialah Facebook/Twitter/Instagram dengan nilai 92,4 $\%$, kemudian Whatsapp/Line/Path serta situs web sebanyak 62,8 \% dan 34,9\% (Mastel, 2019). Hoax pada bidang kesehatan tidak hanya mengancam jiwa seseorang namun juga dapat menyebar jauh lebih cepat dibanding dengan informasi valid. Satu persen hoax yang paling populer akan menyebar ke 1000100.000 orang, sedangkan informasi valid hanya kurang dari 1000 orang (Vosoughi, Roy and Aral, 2018).

Para penyebar hoax merasa bahwa informasi yang dibagikan bermanfaat, harus segera dibagikan serta tanpa niat yang buruk (Hasan, 2017). Survei oleh Masyarakat Telematika Indonesia tahun 2019, juga mengungkapkan bahwa 57,70\% responden memilih edukasi/sosialisasi sebagai langkah untuk menghindari hoax (Mastel, 2019). Kesulitan dalam memahami trend atau pola pengguna dalam mempercayai hoax merupakan fenomena yang menarik untuk mengkaji hoax. Trend pengguna internet yang mempercayai hoax bersifat fluktuatif, pada tahun 2013 sebanyak $50 \%$, tahun 2014 sebanyak 53\%, tahun 2015 sebanyak 51\%, tahun 2016 sebanyak 54\%, tahun 2017 sebanyak 53\% dan tahun 2018 sebanyak $51 \%$ (Barometer, 2018).

Penelitian ini bertujuan untuk mendeskripsikan persepsi masyarakat di RW 10 Kelurahan Tanjung Mas Kecamatan Semarang Utara terhadap berita Hoax Bidang Kesehatan.

\section{METODE}

Penelitian menggunakan jenis penelitian deskriptif-kualitatif. Penelitian deskriptifkualitatif merupakan penelitian yang datanya mengandung kata-kata, gambar maupun bukan angka-angka. Pada penelitian ini, data-data kualitatif akan dideskripsikan apa adanya untuk menggambar hasil data yang empiris serta sebenar-benarnya (Moleong, 2009).

Data yang dikumpulkan ialah data primer dan data sekunder. Data primer merupakan informasi yang didapatkan berdasarkan wawancara mendalam dengan informan yang terdiri dari Ketua RW, Ketua Lembaga Pemberdayaan Masyarakat Kelurahan (LPMK) dan masyarakat sebanyak 3 orang. Wawancara dilakukan secara individu tiap informan, lalu dilanjutkan dengan focus group discussion (FGD). Data sekunder merupakan informasi yang diperoleh berdasarkan tinjauan kepustakaan untuk mendukung atau menguatkan hasil temuan.

Teknik analisis data menggunakan analisis deskriptif-kualitatif. Pada analisis ini, dilakukan dengan tahapan pencarian data, pengorganisasian data, melakukan pemilahan data menjadi satuan yang memiliki nilai, melakukan sintesis, mencari serta menemukan hal yang pentng dan dicari untuk dipaparkan kepada pembaca (Moleong, 2009).

\section{HASIL}

Para informan memberikan penjelasan terkait definisi atau pengertian dari hoax bidang kesehatan. Informan pertama dan kedua bersepakat bahwa hoax bidang kesehatan merupakan informasi yang tidak benar dan tidak dapat dipertanggungjawabkan kebenarannya. Informan ketiga mengungkapkan bahwa hoax bidang kesehatan merupakan berita bohong yang digunakan untuk mendapatkan simpati dari orang lain, sedangkan pada informan keempat dan kelima beranggapan bahwa hoax bidang kesehatan merupakan berita bohong yang ada di media facebook atau whatsapp.

Hoax memiliki dampak bagi mereka yang mempercayai dan ikut menyebarkannya. Kelima informan bersepakat bahwa hoax bidang kesehatan memiliki dampak yang negatif bagi seseorang yang menyebarkan dan mempercayainya. Informan pertama mengungkapkan bahwa hoax bidang kesehatan akan berdampak pada kerugian bagi yang 
mempercayainya. Informan pertama memberikan contoh yaitu seseorang yang mempercayai bahwa pemberian vaksin dapat membahayakan anak. Seseorang tidak memberikan vaksin ke anaknya, akibatnya anak tidak mendapatkan perlindungan dari vaksin tersebut. Hal ini akan berbahaya bagi anak tersebut. Sedangkan, informan kedua lebih menyoroti dampak dari hoax kesehatan berupa sanksi atau hukuman yang diberikan oleh penyebar hoax bidang kesehatan. Informan ketiga, keempat dan kelima mengungkapkan hal yang sama mengenai dampak hoax yaitu menghambat tugas dari tenaga kesehatan. Masyarakat menjadi percaya atas informasi kesehatan yang disampaikan oleh orang lain ketimbang tenaga kesehatan.

Kelima informan juga menyepakati bahwa media yang paling sering dijumpai berita hoax bidang kesehatan yaitu facebook dan whatsapp group. Informan kedua mengungkapkan bahwa pesan yang diteruskan di whatsapp group memiliki kecenderungan sebagai hoax karena sumbernya tidak jelas. Sedangkan menurut informan ketiga dan keempat, mereka yang menyebarkan informasi kesehatan di facebook yang bukan tenaga kesehatan / ahlinya memiliki kecenderungan sebagai informasi hoax.

Para informan juga menjelaskan mengenai beberapa hoax bidang kesehatan yang paling sering mereka terima. Informan pertama menyatakan bahwa informasi mengenai pengobatan alternatif sering ditemui sebagai hoax kesehatan (mis; memijat jari jempol kaki dapat mengobati kanker). Informan kedua lebih sering menerima hoax bidang kesehatan berupa larangan terhadap sesuatu karena berdampak pada kesehatan (mis; larangan untuk mengonsumsi MSG karena berbahaya untuk otak). Informan ketiga mengungkapkan bahwa informasi mengenai larangan untuk mengonsumsi sesuatu secara bersamaan (mis; larangan untuk mengonsumsi mie instan dan cokelat secara bersamaan yang dapat menyebabkan keracunan) sering mereka terima. Informan keempat dan kelima memiliki kesamaan atas hoax bidang kesehatan yang paling sering diterima yaitu manfaat obat herbal (mis; daun sirsak dapat mengobati kanker)
Beberapa cara dapat dilakukan untuk mengatasi penyebaran hoax bidang kesehatan. Informan pertama dan kedua mengungkapkan bahwa hal yang paling utama untuk mengatasi hoax kesehatan ialah dengan gencar melakukan sosialisasi/edukasi. Informasi yang salah harus dilawan dengan informasi yang benar. Para ahli di bidang kesehatan harus bisa menjelaskan kepada masyarakat mengenai informasi yang benar tersebut. Sedangkan, informan ketiga dan keempat lebih menyoroti penegakan sanksi atau hukuman kepada para penyebar hoax bidang kesehatan. Hal ini dapat dijadikan sebagai efek jera bagi pelaku, sehingga masyarakat menjadi takut untuk menyebarkan informasi yang masih diragukan kebenarannya. Sementara itu, informan kelima lebih menitikberatkan kesadaran diri sendiri untuk tidak menyebarkan informasi kesehatan yang tidak diketahui. Upaya mengatasi penyebaran hoax dapat dilakukan oleh tiap individu, dengan cara menahan diri untuk tidak membagikan informasi.

\section{PEMBAHASAN}

Hoax pada bidang kesehatan merupakan informasi kesehatan yang tidak dapat dipertanggungjawabkan kebenarannya. Keseluruhan informan telah memahami pengertian ini. Hanya pada informan ketiga lebih berfokus pada alasan penyebaran hoax, sedangkan pada informan keempat dan kelima lebih berfokus pada media penyebaran hoax kesehatan. Namun secara umum, semua informan telah memahami definisi dari hoax bidang kesehatan. Macdougall menambahkan pengertian hoax sebagai informasi yang tidak benar, namun dibuat seolah-olah benar (MacDougall, 1958). Beberapa dampak hoax yang ditemukan pada literatur misinformasi terhadap komunikasi krisis ebola di Amerika Serikat. Pada artikel tersebut ditemukan bahwa pesan di media sosial yang keliru dapat menghambat penanganan ebola di Amerika Serikat (Sell, Hosangadi and Trotochaud, 2020).Hal ini berkaitan dengan pendapat informan pertama yang mengungkapkan bahwa hoax mendatangkan kerugian bagi yang mempercayainya. Sementara itu, dampak hoax lainnya yaitu sanksi atau hukuman bagi pelaku yang 
menyebarkan berita bohong didepan umum dan bertentangan dengan kebenaran yang ada berdasarkan ketentuan Undang Undang Nomor 19 Tahun 2016 tentang Informasi dan Transaksi Elektroni (Rimadhini, 2018). Hal ini sesuai dengan pendapat informan kedua. Dampak hoax kesehatan yang lainnya yaitu informasi kesehatan palsu mengakibatkan pasien meragukan diagnosa dari dokter dan pekerjaan dokter menjadi lebih sulit (Johnson et al., 2017). Tenaga kesehatan harus mengoreksi informasi yang salah serta mengembalikan kepercayaan pasien. Hal ini sejalan dengan pendapat informan ketiga, keempat dan kelima.

Media yang paling sering digunakan untuk penyebaran hoax bidang kesehatan yaitu Facebook/Twitter/Instagram dengan nilai 92,4 $\%$, kemudian Whatsapp/Line/Path serta situs web sebanyak 62,8\% (Mastel, 2019). Hal ini sesuai dengan pendapat informan yang menyatakan bahwa Facebook dan Whatsapp Group menjadi media yang paling sering dijumpai hoax.

Hoax bidang kesehatan yang paling sering didengar oleh informan yaitu pengobatan alternatif, larangan terhadap sesuatu dan larangan untuk mengonsumsi sesuatu secara bersamaan. Detikhealth merangkum 10 hoax kesehatan paling sering beredar di Facebook dan Whatsapp yang didominasi oleh pesan-pesan pengobatan alternatif, larangan untuk mengonsumsi sesuatu secara bersamaan dan larangan terhadap sesuatu yang membahayakan kesehatan (Anwar, 2019).

Beberapa cara yang dapat dilakukan untuk pencegahan informasi hoax yaitu dengan meningkatkan kemampuan literasi media. Upaya edukasi dan sosialisasi dapat meningkatkan kemampuan untuk memahami dan menganalisis isi berita (Gumilar, 2017).

\section{SIMPULAN}

1. Hoax bidang kesehatan merupakan informasi kesehatan yang tidak dapat dipertanggungjawabkan kebenarannya.

2. Dampak dari hoax bidang kesehatan yaitu merugikan bagi yang mempercayainya, terdapat sanksi atau hukuman serta menghambat tugas dari tenaga kesehatan

3. Media yang paling sering dijumpai hoax yaitu Facebook dan Whatssapp Group.

4. Hoax yang paling sering dijumpai oleh informan yaitu pengobatan alternati larangan terhadap sesuatu dan larangan untuk mengonsumsi sesuatu secara bersamaan

5. Cara yang dapat dilakukan untuk menghindari hoax bidang kesehatan yaitu edukasi/sosialisasi dan penegakan hukum

\section{DAFTAR PUSTAKA}

Anwar, F. (2019) 10 Hoax Kesehatan yang Sering Beredar di Whatsapp dan Facebook, DetikHealth. Available at: https://health.detik.com/beritadetikhealth/d-4436167/10-hoaxkesehatan-yang-sering-beredar-diwhatsapp-dan-facebook.

Barometer, E. T. (2018) Edelman Trust Barometer Global Report.

Gumilar, G. (2017) 'Literasi media: Cerdas menggunakan media sosial dalam menanggulangi berita palsu (hoax) oleh siswa SMA', Jurnal Pengabdian Kepada Masyarakat, 1(1).

Hasan (2017) Kesehatan. Available at: https://tirto.id/info-hoax-soal-kesehatanpaling-banyak-beredar-di-masyarakatcnQZ.

Indonesia, P. W. (2017) Penelitian Hoax di Indonesia. Jakarta.

Johnson, S. B. et al. (2017) 'Use of Alternative Medicine for Cancer and Its Impact on Survival', JNCI: Journal of the National Cancer Institute, 110(1), pp. 121-124. doi: 10.1093/jnci/djx145.

MacDougall, C. D. (1958) Hoaxes. Dover Pubns.

Mastel (2019) 'Hasil Survey Wabah Hoax Nasional 2019', Website Masyarakat 
Telematika Indonesia, p. 35. Available at: https://mastel.id/hasil-survey-wabahhoax-nasional-2019/.

Moleong, J. (2009) 'Lexy', Metodologi Penelitian Kualitatif, pp. 107-108.

Rimadhini, C. P. (2018) 'Pertanggungjawaban Pidana Penyebaran Berita Bohong (Hoax) Melalui Media Elektronik (Studi Analisis Beredarnya Konten Video Telur Palsu Oleh Syahroni Daud)'. Universitas Islam Indonesia.

Sell, T. K., Hosangadi, D. and Trotochaud, M. (2020) 'Misinformation and the US Ebola communication crisis: analyzing the veracity and content of social media messages related to a fear-inducing infectious disease outbreak', $B M C$ Public Health. BioMed Central, 20(1), pp. 1-10.

Vosoughi, S., Roy, D. and Aral, S. (2018) 'News On-line', Science, 1151(March), pp. 1146-1151. 